\title{
MATERNAL OPHTHALMIC ARTERY DOPPLER VELOCIMETRY IN NORMOTENSIVE PREGNANCY AND PREGNANCIES COMPLICATED BY HYPERTENSION
}

Ankur Aggarwal ${ }^{1}$, Hemant Kumar Mishra², Sunny Goyal ${ }^{3}$, Tushar Prabha ${ }^{4}$, Vipin Kumar Bakshi ${ }^{5}$

\section{HOW TO CITE THIS ARTICLE:}

Ankur Aggarwal, Hemant Kumar Mishra, Sunny Goyal, Tushar Prabha, Vipin Kumar Bakshi. "Maternal Ophthalmic Artery Doppler Velocimetry in Normotensive Pregnancy and Pregnancies Complicated by Hypertension". Journal of Evolution of Medical and Dental Sciences 2014; Vol. 3, Issue 59, November 06; Page: $13354-13359$, DOI: $10.14260 /$ jemds/2014/3781

ABSTRACT: Hypertensive disease occurs in 5-15\% of all pregnancies and continues to cause significant maternal morbidity and mortality associated with neonatal morbidity and mortality. Hypertension is a sign of underlying pathology which may be pre-existing or appears for the first time during pregnancy. Here we report a series of 100 pregnant females (normotensive as well as hypertensive) from gestational age 20 weeks to 40 weeks. Aim of our study was to compare doppler velocimetric value of maternal ophthalmic artery in normotensive pregnancy and pregnancies complicated by hypertension.

KEYWORDS: Ophthalmic artery, pre eclampsia, RI (Resistivity index), PI (Pulsatility index)

INTRODUCTION: Pre-eclampsia is a multiorgan disease characterized by regional vasospasm with hypertension arising in pregnancy (Pregnancy induced hypertension) in association with significant ampounts of protein in the urine. ${ }^{1}$

For the past 20 years, Doppler velocimetry has been used to study orbital circulation and to assess ocular and retro-bulbar diseases.2,3 The technique is useful for both quantitative and qualitative evalua- tion of orbital circulation. ${ }^{4,5}$ Initially, the method was restricted to the study of ophthalmic diseases; however, it has been proposed as an instrument to aid the propedeutics of systemic diseases such as pre-eclampsia. ${ }^{6}$ owing to the similarity of orbital and intracranial circulation. The ophthalmic artery, which is responsible for the orbital blood supply, is a direct branch of the internal carotid artery and is part of the shunt between the internal and external

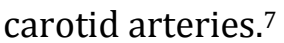

\section{CLASSIFICATION:}

- Gestational hypertension- without proteinuria or pathological oedema.

- Pre eclampsia- hypertension and proteinuria with or without pathological oedema.

- Eclampsia- pre eclampsia complicated with convulsions and/or coma.

- Chronic hypertension.

- Preeclampsia or eclampsia superimposed on chronic hypertension.

Assessment of the cerebral circulation is challenging. Noninvasive techniques, especially transcranial Doppler sonography, are becoming more widely used.7 Doppler sonography of the ophthalmic artery is a noninvasive method used to study central territory vascular flow during pregnancy.8,9 Hata et $\mathrm{al}^{10}$ in 1992 were the first to use ophthalmic artery Doppler sonography in the 
assessment of pregnant women. Since then, several authors have evaluated this method during pregnancy, especially in women with hypertension.8,9

\section{AIMS AND OBJECTIVES:}

OBJECTIVE: To compare maternal ophthalmic artery doppler velocimetry in normotensive pregnancies and pregnancies complicated by hypertension.

\section{AIM:}

a. To identify the ophthalmic artery and to study its velocity parameters by colour doppler ultrasound.

b. To compare the velocity parameters in different patients of normotensive and hypertensive pregnancies.

c. To observe whether there is a correlation between velocity parameter and maternal blood pressure.

\section{MATERIAL AND METHODS:}

- Total number of hundred patients were studied. Among them 50 normotensive pregnant mother and 50 pregnancy with hypertension patients referred from Gynaecology and Obstetrics Department.

- Ultrasound Machine- TOSHIBA 5510X.

- Ultrasound Probes- Linear probe of frequency 7.5 to12 Mhz.

\section{Patient Selection Criteria:}

Inclusion Criteria: All pregnant women in their second and third trimester gestation period (20 weeks till term) will be included in this study that were previously normotensive before pregnancy or with history of hypertension induced by the pregnancy.

\section{Exclusion Criteria:}

a. Patients with history of any known cardiac disorders like congenital heart disease.

b. Known case of Diabetes mellitus.

c. Patients having congenital foetal malformation.

d. Twin pregnancy and molar pregnancies.

Study Design: Total number of hundred patients was studied. Among them 50 normotensive pregnant mother and 50 pregnancy with hypertension patients.

\section{DISCUSSION AND CONCLUSION:}

1. Preeclampsia occurs more commonly in younger age group patients. Our results were comparable with study conducted by Correa Silva et al, ${ }^{11}$ and Onaran et al. ${ }^{12}$

2. Preeclampsia is more common in primigravid patients who are pregnant for the first time. Our results were similar to study done by Correa Silva et al ${ }^{11}$ which showed $65 \%$ were primigravida.

3. Preeclampsia occurs more commonly in nulliparous women who have had no previous live birth. Fernanda Surita et al, ${ }^{11}$ showed that $66.7 \%$ hypertensive patients were nulliparous in 
their study which is almost similar to our study.

4. Preeclampsia is more common in patients who had history of hypertension in previous pregnancy and positive history of hypertension in the family. Similar results were obtained by study done by Kooffreh et al.

5. Headache is the most common symptom in the patients presenting with preeclampsia and the second common symptom is edema. Similar results were obtained in study done by Ravi Ranjan et $\mathrm{al}^{13}$ and Manjusha Sajith et al. ${ }^{14}$

6. The mean arterial pressure in preeclampsia is significantly higher than that of normal pregnancy. Our findings are comparable with the study done by Onaran et al. ${ }^{12}$

7. Preeclampsia usually develops in late pregnancy during third trimester of the pregnant women.

8. Both RI and PI decreased in preeclampsia as compared to normal pregnancy due to the effect of vasodilatation and orbital hyper perfusion in preeclampsia. Similar results were obtained on study done by Manjusha Sajith et al. ${ }^{14}$

9. The resistivity index of ophthalmic artery showed an inverse correlation with mean arterial pressure of pregnant women. Our findings were comparable with the study done by Ayaz et $\mathrm{al}^{1}$ and Diniz et al. ${ }^{9}$

10. The pulsatility index of ophthalmic artery showed an inverse correlation with the mean arterial blood pressure of pregnant women. Our findings were comparable with the study done by Hata et al.16

11. Most number of pregnancy induced hypertension patients after follow up developed preterm labour and intrauterine growth restriction. Eclampsia was seen only in minority in our study. Similar results were obtained by study done by Sachan et al ${ }^{17}$ and Maimoona Ahmed et al. ${ }^{18}$

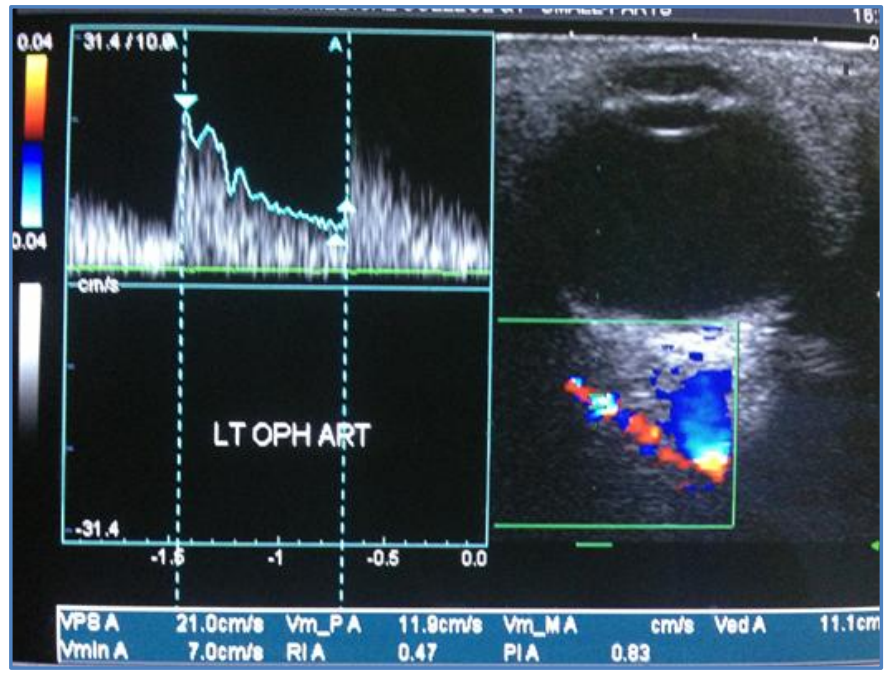

HYPERTENSIVE PATIENT OPHTHLAMIC ARTERY DOPPLER 


\section{CASE REPORT}

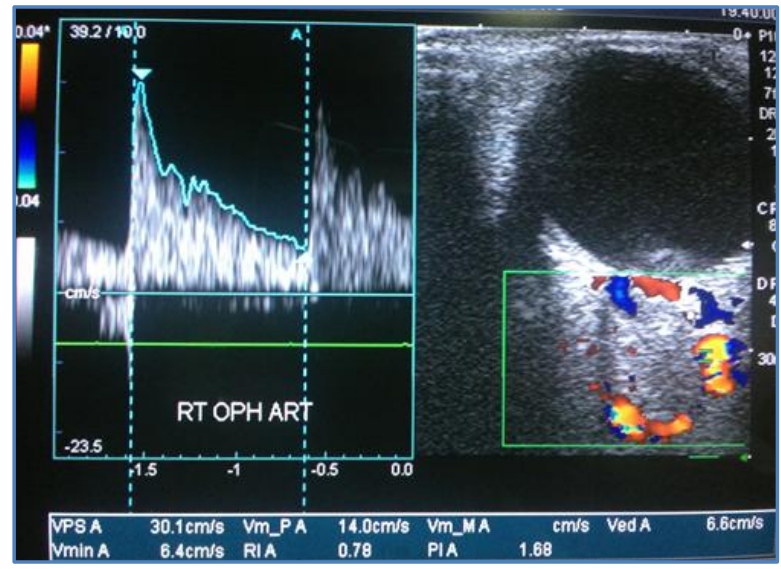

NORMOTENSIVE PATIENT

OPHTHLAMIC ARTERY DOPPLER

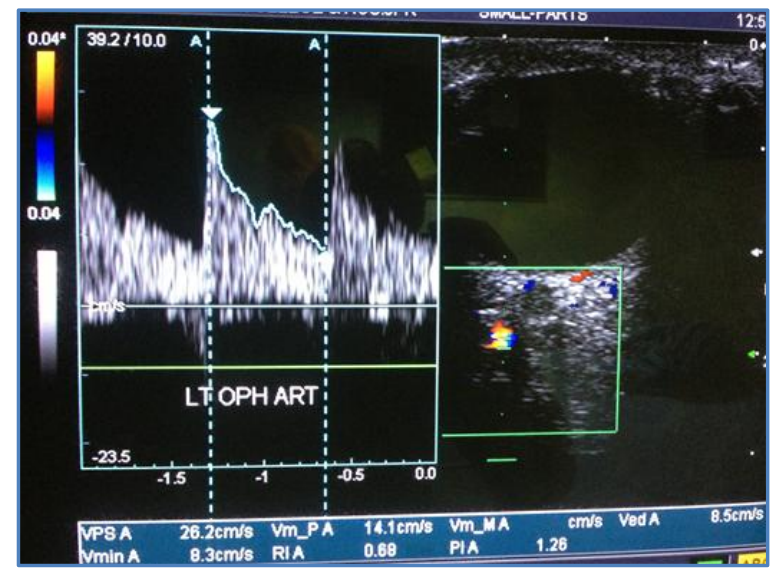

HYPERTENSIVE PATIENT OPHTHALMIC ARTERY DOPPLER

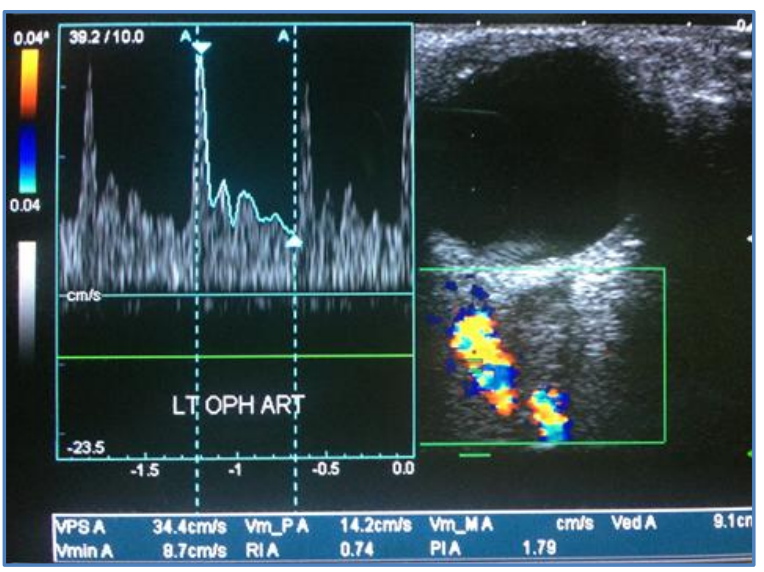

NORMOTENSIVE PATIENT OPHTHLAMIC ARTERY DOPPLER 


\section{REFERENCES:}

1. Riskin-Mashiah S, Belfort MA, Sade GR, Herd AJ. Side-to-side differences in transcranial Doppler parameters in normotensive and preeclamptic pregnant women. Am J Obstet Gynecol 2004; 190: 194-8.

2. Canning CR, Restori M. Doppler ultrasound studies of the ophthalmic artery. Eye (Lond) 1988;2(Pt 1):92-5

3. Erickson SJ, Hendrix LE, Massaro BM, Harris GJ, Lewandowski MF, Foley WD, et al. Color Doppler flow imaging of the normal and abnormal orbit. Radiology 1989; 173 (2):511-6.

4. Baxter GM, Williamson TH. Color Doppler imaging of the eye: normal ranges, re- producibility, and observer variation. J Ultrasound Med 1995; 14 (2): 91-6.

5. Guthoff RF, Berger RW, Winkler P, Helmke K, Chumbley LC. Doppler ultrasonogra- phy of the ophthalmic and central retinal vessels. Arch Ophthalmol 1991; 109 (4): 532-6.

6. Kaneda H, Irino T, Arita N, Minami T, Taneda M, Shiraishi J. Relationship between ophthalmic artery blood flow and recanalization of occluded carotid artery. Ultra- sonic Doppler study. Stroke 1978;9(4):360-3.

7. Silva FC, Sá RAM, Velarde LGC, Suarez B, Ville Y. Doppler sonography of maternal cerebral arteries in pregnancy: side-to-side differences. Gynecol Obstet Invest2011; 72:25-31 Vol 5 No 04 Apr 2014; 163-170.

8. De Oliveira CA, de Sá RAM, Velarde LGC, Marchiori E, Netto HC, Ville Y. Doppler velocimetry of the ophthalmic arteries in pregnancy: reference values. J Ultrasound Med2009; 28:563-569.

9. Diniz AL, Moron AF, dos Santos MC, Sass N, Pires CR, Debs CL. Ophthalmicartery Doppler as a measure of severe pre-eclampsia. Int J GynaecolObstet 2008; 100: 216-20

10. Hata T, Senoh D, Hata K, Kitao M. Ophthalmic artery velocimetry in pregnant women. Lancet1992.

11. EP Correa Silva,Fernanda G. Surita $\square$, Cristiane Barbieri, Sirlei S. Morais, José G. Cecatti Reference values for Doppler velocimetry of the ophthalmic and central retinalarteries in lowrisk pregnancy, IJG-07218

12. Zafer Onaran,Yasem, Karaden ,Yılmazbas, Retrobulbar Hemodynamics in Pregnancy Gazi Med J2012; 23: 55-8.

13. Ravi Ranjan, Sriti Sinha, Shikha Seth Fundus Changes and Fetal Outcomes in Pregnancy Induced Hypertension: An Observational Study Int J Sci Stud 2014;2(7):6-9.

14. Manjusha sajith,Vandana nimbargi, Amit modi, Ronak sumariya, Incidence of pregnancy induced hypertension and prescription pattern of antihypertensive drugs in pregnancy International Journal of Pharma Sciences and Research

15. Ayaz T, Akansel G, Hayirlioglu A, Arslan A, Suer N, Kuru I. Ophthalmic artery color Doppler ultrasonography in mild-to-moderate preeclampsia. Eur J Radiol 2003; 46: 244-9.

16. Hata T, Hata K, Moritake K. Maternal ophthalmic artery Doppler velocimetryin normotensive pregnancies and pregnancies complicated by hypertensivedisorders. Am J Obstet Gynecol 1997; 177: $174-8$

17. Rekha Sachan, Munna Lal Patel, Pushpalata Sachan, Amrita Gaurav. Outcomes in hypertensive disorders of pregnancy in the North Indian populationInternational Journal of Women's Health 2013:5 101-108. 
18. Maimoona Ahmed, Rekha G. Daver Study of Feto-Maternal Outcome in Pregnancy Induced Hypertension Global Journal of Medical research: E Gynecology and Obstetrics 2014; 14(1): 21-25

\section{AUTHORS:}

1. Ankur Aggarwal

2. Hemant Kumar Mishra

3. Sunny Goyal

4. Tushar Prabha

5. Vipin Kumar Bakshi

\section{PARTICULARS OF CONTRIBUTORS:}

1. P. G. Resident, Department of Radiodiagnosis, Mahatma Gandhi Medical College and Hospital, Jaipur.

2. Professor and HOD, Department of Radiodiagnosis, Mahatma Gandhi Medical College and Hospital, Jaipur.

3. P. G. Resident, Department of Radiodiagnosis, Mahatma Gandhi Medical College and Hospital, Jaipur.
4. Senior Resident, Department of Radiodiagnosis, Mahatma Gandhi Medical College and Hospital, Jaipur.

5. P. G. Resident, Department of Radiodiagnosis, Mahatma Gandhi Medical College and Hospital, Jaipur.

\section{NAME ADDRESS EMAIL ID OF THE} CORRESPONDING AUTHOR:

Dr. Ankur Aggarwal,

Room Number 204, PG Hostel, MGMCH, Sitapura, Jaipur-302022.

Email: drankur88@yahoo.com

Date of Submission: 15/10/2014. Date of Peer Review: 16/10/2014. Date of Acceptance: 05/11/2014. Date of Publishing: 06/11/2014. 